\title{
Sumari
}

Papers. Revista de Sociologia

Juliol-setembre 2011, vol. 96, núm. 3, p. 623-1023, ISSN 0210-2862

Les paraules clau són en llenguatge lliure

http://ddd.uab.cat/record/35

627-629 Presentación

\section{Articles Monogràfic}

Inmigración e integración sociolaboral en España y Estados Unidos

633-655 KopinaK, Kathryn (King's University College)

How Maquiladora Industries Contribute to Mexico-U.S. Labor Migration. Papers, 2011, vol. 96, núm. 3, p. 633-655.

Key words: Maquiladora industries; social capital; human capital; border regions; emigration; skill transfer; exports.

657-681 Trinidad Requena, Antonio (Universidad de Granada)

La mirada emergente: el discurso de los procesos de integración. Papers, 2011, vol. 96, núm. 3, p. 657-681.

Palabras clave: inmigrantes; España; integración social; políticas de integración social; convivencia; redes sociales.

683-705 Soriano-Miras, Rosa M. (Universidad de Granada)

Análisis sociológico de la Ley 4/2000, de 11 de enero, sobre derechos y libertades de los extranjeros en España y su integración social. Sus reformas $(8 / 2000,11 / 2003,14 / 2003,2 / 2009)$ y su implicación social. Papers, 2011, vol. 96, núm. 3, p. 683-705.

Palabras clave: extranjería; inmigración; xenofobia; identidad; política migratoria; integración social.

707-730 Fernández Castaño, Félix (Universidad de Granada)

Formación profesional reglada para mujeres y hombres inmigrantes. El caso de la ciudad de Granada. Papers, 2011, vol. 96, núm. 3, p. 707-730.

Palabras clave: inmigración; formación profesional reglada; comunidad educativa; Granada: Granada (provincia). 
731-755 Relaño Pastor, Ana M. (Universidad de Castilla-La Mancha); Mijares, Laura (Universidad Complutense de Madrid)

Through U.S. Eyes: Examining Spanish Multilingual Education Policies. Papers, 2011, vol. 96, núm. 3, p. 731-755.

Key words: multilingualism; language policy; immigration; education; ethnography; United States of America; Spain.

757-780 Morcillo Espina, Álvaro (Universidad de Navarra)

El debate entre transnacionalismo y nacionalismo metodológico como marco teórico para la comprensión del papel del empleo en la gobernabilidad de la inmigración en España. Papers, 2011, vol. 96, núm. 3, p. 757-780.

Palabras clave: teoría social; política de inmigración; integración social; cooperación al desarrollo; gobernabilidad; ciudadanía; estado nacional; globalización; comunidades autónomas.

781-803 Massey, Douglas S. (Princeton University); Connor, Philip (Pew Research Center); DuRAND, Jorge (Universidad de Guadalajara)

Emigration from Two Labor Frontier Nations: A Comparison of Moroccans in Spain and Mexicans in the United States. Papers, 2011, vol. 96, núm. 3, p. 781-803.

Key words: immigration; foreign workers; Morocco; Mexico; human resources; social capital; comparative analysis; ethnosurvey questionnaire.

805-824 Hondagneu-Sotelo, Pierrette; Estrada, Emir; Ramírez, Hernán (Universidad del Sur de California)

Más allá de la domesticidad. Un análisis de género de los trabajos de los inmigrantes en el sector informal. Papers, 2011, vol. 96, núm. 3, p. 805-824.

Palabras clave: sector informal; género; trabajadores inmigrantes; masculinidades; juventud.

825-852 Alemán Bracho, María del Carmen (UNED)

Inmigración y servicios sociales. Papers, 2011, vol. 96, núm. 3, p. $825-852$.

Palabras clave: integración social; política social; redes sociales; España.

853-881 Susino Arbucias, Joaquín (Universidad de Granada)

La evolución de las migraciones interiores en España: una evaluación de las fuentes demográficas disponibles. Papers, 2011, vol. 96, núm. 3, p. 853-881.

Palabras clave: migración interior; fuentes demográficas; censo de población; padrón municipal; encuestas demográficas; migraciones; migrantes. 
883-911 Martínez Martín, Rafael; Prior Ruiz, Juan Carlos (Universidad de Granada)

La inserción socioprofesional de los inmigrantes en Andalucía. Papers, 2011, vol. 96, núm. 3, p. 833-911.

Palabras clave: inmigración; mercado de trabajo; inserción profesional; integración social.

\section{Articles Miscel-lànic}

915-936 SANCHIS, Enric (Universitat de València)

Prostitución voluntaria o forzada. Una contribución al debate. Papers, 2011, vol. 96, núm. 3, p. 915-936.

Palabras clave: coerción; constricción estructural; trabajo sexual; abolicionismo; derechos laborales; políticas públicas; España.

937-957 BRUNET, Ignasi (Universitat Rovira i Virgili)

L'esperit empresarial des de la perspectiva del gènere. Papers, 2011, vol. 96, núm. 3, p. 937-957.

Paraules clau: gènere; creació d'empreses; conciliació laboral; empresàries.

959-983 UrTeaga, Eguzki (Universidad del País Vasco)

Las rentas mínimas en Francia. Papers, 2011, vol. 96, núm. 3, p. 959-983.

Palabras clave: política social; prestaciones sociales; renta mínima; Francia.

985-1006 Ajenjo Cosp, Marc; García Román, Joan (Universitat Autònoma de Barcelona)

El tiempo productivo, reproductivo y de ocio en las parejas de doble ingreso. Papers, 2011, vol. 96, núm. 3, p. 995-1016.

Palabras clave: parejas de doble ingreso; género; uso del tiempo.

1007-1013 Ressenyes

Almeda Samaranch, Elisabet (coord.). Diàlegs per la memòria (Rafael Ramis Barceló).

Novick, Susana (dir.) Migraciones y MERCOSUR: una relación inconclusa (Graciela Sarrible Pedroni).

Normes de publicació a Papers. Revista de Sociologia

Normas de publicación en Papers. Revista de Sociologia

Guidelines for publication in Papers. Revista de Sociologia 